\title{
CURADORIA E MEDIAÇÃO TECNOLÓGICA COM QR-CODES: \\ CASOS MUSEOGRÁFICOS NO \\ CONTEXTO BRASILEIRO
}

David Ruiz Torres'

\begin{abstract}
RESUMO
Neste trabalho se realiza um estudo sobre a utilização dos QR-codes em dois espaços expositivos na cidade de Vitória (ES). A análise comparativa de ambas experiências permitiu avaliar criticamente $\circ$ uso desta ferramenta tecnologica como recurso educacional para a mediação e a difusão da arte, assim como a busca de variantes ou alternativas ao modelo proposto.
\end{abstract}

\section{PALAVRAS-CHAVE}

QR-code, mediação, arte, exposição.

\author{
CURATORIAL PRACTICES AND \\ TECHNOLOGICAL MEDIATION \\ WITH QR-CODES: MUSEOGRAPHIC \\ CASES IN THE BRAZILIAN CON- \\ TEXT
}

\section{ABSTRACT}

This work is a study about the use of QRcodes in two exhibition spaces in the city of Vitória (ES). The comparative analysis of both experiments allowed critically evaluate the use of this technology as an educational resource tool for mediation and dissemination of art, as well as the search for variants or alternatives to the proposed model.

\section{KEYWORDS}

QR-code, mediation, art, exhibition.

\footnotetext{
' Doutor em Arte pela Universidade de Granada; pós-doutorando em Artes pela Universidade Federal do Espírito Santo.
} 


\title{
Mediação e novas tecnologias nos espaços expositivos do século XXI
}

No início do século $X X I$, os muitos avanços tecnológicos conduziram o ser humano, alterando a sua então construção histórica, a mudar a sua forma de existência, apresentando um modelo de vida on-line e off-line como parte de um mesmo ente. Em nosso presente, a diferenciação entre o mundo real e o virtual está se tornando cada vez mais anacrônica já que a presença da tecnologia faz parte de nossas vidas diárias e até mesmo de nossa natureza além do meramente físico no que tem sido denominado como um processo de "cibridismo".

Uma nova realidade que está intimamente ligada a algumas mudanças em nossa consciência e na forma de articular o nosso pensamento no qual esta ciber-realidade se apresenta como parte integrante de nosso ser, levando a uma redefinição de como poderíamos viver juntos no espaço entre o virtual e o real. Isso tem a ver também com o conceito desenvolvido por Roy Ascott de "ciberpercepção":

\begin{abstract}
as tecnologias pós-biológicas nos permitem estar diretamente envolvidos na nossa própria transformação, e estão a provocar uma mudança qualitativa em nosso ser. A faculdade emergente de ciberpercepção, nossas artificialmente melhoradas interações de percepção e cognição, envolvem a tecnologia transpessoal de redes e cibermídia globais (1996: 2, tradução nossa).
\end{abstract}

Portanto, a presença cada vez maior das tecnologias não deve ser entendida como simplesmente $o$ uso de ferramentas que facilitam a realização de algumas tarefas, mas também se refere a uma melhora na nossa aprendizagem e nos modos de como enfrentar e pensar a realidade.

Assim, não é surpreendente que uma das instituições da memória e do saber, os museus, tenham sucumbido a uma implantação significativa das novas tecnologias desde sua aparição, como estratégia de aprimoramento nas suas ações de mediação na e da cultura.

Os espaços expositivos do século $X X I$, museográficos ou não, têm sido caracterizados por uma crescente utilização das tecnologias contemporâneas em campos relativos à documentação, restauração ou comunicação. $A$ área de mediação educacional não poderia ser menos afetada por esses novos ventos, e até a data existe uma dinâmica importante na utilização de recursos tecnológicos que facilitam esse trabalho interpretativo e de difusão, tanto aos profissionais quanto ao público.

A nossa forma de adquirir conhecimento, baseado no conceito de interatividade, entendida como a interação entre o indivíduo e a máquina, se concebe como sinônimo de aprendizagem no âmbito museológico. A uma grande quantidade de ferramentas tecnológicas, tais como painéis ao toque (touch screan), jogos interativos ou reconstruções virtuais em 3D; devemos acrescentar todas aquelas que têm proliferado graças ao uso do telefone celular nos últimos anos: aplicativos multimédia personalizados, QR-codes, ou, mais recentemente, a realidade aumentada.

No entanto, e como observado por Ana Mae Barbosa "a área menos beneficiada pelas tecnologias contemporâneas em museus é a educacional” (2005: 109), destacando o frágil estado da tecnologia no campo da mediação.

Assim, parece que a tendência ainda presente em nossa maneira de visitar os espaços expositivos se deriva de um tratamento reducionista do discurso museugráfico no qual a obra se minimiza ao seu senso estético ou significado parcial.A existência deste pensamento resultaria, em muitos casos, em um desa- 
proveitamento do potencial que as tecnologias oferecem para a mediação dentro destes espaços obviando a importância do contexto da obra para entender a mensagem.

Uma situação que é paralela à falta de estudos de público para avaliar o impacto real dos conteúdos virtuais oferecidos aos visitantes. Assim, a relação entre os conteúdos digitais e o público não tem conseguido ter uma atenção especial, desde que fizeram sua aparição os chamados museus virtuais. Foi algo que já se mencionava na obra de Wernet Schweibenz, The virtual museum, quando afirmou que "enquanto os estudos visitantes tornaram-se uma disciplina emergente no campo museológico Anglo-Americano, as pesquisas destinadas aos visitantes virtuais são um campo comparativamente novo" (1996: 193, tradução nossa).

Apesar das quase duas décadas que nos separam destas afirmações, o fato é que os estudos de público virtual ainda não conseguiram ter a mesma notoriedade que os estudos tradicionais de público ou ir mais além de meros dados quantitativos. Algo que também se repite na avaliação dos recursos tecnológicos utilizados em salas de exposição, especialmente nos últimos anos em que o conteúdo digital é oferecido através de aplicativos para celular, como mencionaremos a seguir.

Certamente, o interesse suscitado pelas novas tecnologias nas salas de exposição é devido, em muitos casos, a uma moda tecnológica que parece não responder a critérios educativos firmes. Esta ideia já foi denunciada por Edward P. Alexander, em seu trabalho Museums in Motion, quando ele disse que "os dispositivos (tecnológicos) são ferramentas e técnicas para comunicar ideias e conceitos claramente definidos, não truques para ser admirados por sua novidade e inventiva" (1979: 189, tradução nossa). Ele outorgava ao curador a responsabilidade na concepção desses conteúdos, além do correto aproveitamento dos novos recursos tecnológicos.

Ana Mae Barbosa incide sobre esta prática errônea das ferramentas tecnológicas, quando nos fala sobre a "defasagem entre avanço tecnológico e qualidade conceitual que está agora ocorrendo com a maioria dos produtos de museus e de centros culturais, gerados pelas tecnologias contemporâneas, que pretendem dar acesso à obra de arte" (2005: 105).

Esta situação levou ao surgimento de críticas e questionamentos derivados do uso em massa das tecnologias contemporâneas nesses espaços ou, por outro lado, aplicações carentes de conteúdos que ampliem o conhecimento para além do "efeito pirotécnico", o que parece evidenciar uma falta de estudos de público precisos para avaliar a sua viabilidade.

\section{Uso dos QR-code no contexto brasileiro: casos museográficos}

$\mathrm{Na}$ atualidade, a aplicação dos QR--code ${ }^{2}$ tem sido usada como acesso a um link ou endereço específico da Web, sem a necessidade de digitar uma URL no nosso dispositivo celular. Assim, graças à capacidade de acessar informações hospedadas na Internet, os QR-Codes se espalharam em muitas áreas de nossas vidas diárias, expandindo seu crescimento no uso industrial, campanhas de marketing, bibliotecas, armazéns, salas de exposições, etc.

Sua evidente onipresença nas cidades do século XXI como intermediários

\footnotetext{
${ }^{2}$ Para dar uma descrição em relação aos QR-Codes, podemos dizer que são códigos bidimensionais que, diferente dos códigos de barras popularmente mais conhecidos, contém a capacidade de transmitir mais informações. Isto se deve à forma de armazená-la, já que a leitura do código de barras pode apenas ser feita horizontalmente, enquanto que o QR-Code permite leituras vertical e horizontalmente.
} 
entre o real e o digital, levou a serem chamados por Giselle Beiguelman como "a primeira forma de escrita desenvolvida pra leitores nômades" (2013: 149), referindo-se também à crescente tendência do uso de dispositivos portáteis, já que outro fator elemento chave na expansão dos QR-Codes, foi a conjunção com os dispositivos de telefonia móveis, o que produziu a chegada e conhecimento ao público em geral. $O$ surgimento de vários aplicativos para celular, que atuavam como leitores de QR-Code, permitiram expandir exponencialmente seu uso. Essa é uma realidade que foi acrescentada com a recente utilização de dispositivos portáteis em nossa sociedade, especialmente nos últimos anos com a proliferação de smartphones e tablets.

Ainda que não há dados específicos do uso dos QR-code no Brasil, estima-se que têm aumentado recentemente paralelamente à proliferação de dispositivos portáteis como refletiram os dados do Instituto Brasileiro de Geografia e Estatística em sua mais recente pesquisa da PNAD 20I3. Os resultados mostraram que:

\begin{abstract}
o contingente de pessoas de 10 anos ou mais de idade que tinham telefone móvel celular para uso pessoal era de 130,2 milhões, o que correspondia a $75,2 \%$ da população do País nessa faixa de idade. Em relação a 2005, esse contingente aumentou 131,4\% (73,9 milhões de pessoas), enquanto em relação a 2008 o aumento foi de $49,4 \%$ (43,0 milhões de pessoas) (IBGE, 20I5).
\end{abstract}

Assim, hoje pode ser considerado que o QR-Code tem expandido o seu alcance no contexto brasileiro, como evidenciado pelas diversas formas de uso dessa tecnologia em nosso dia a dia sendo uma delas como ferramenta de mediação nos espaços expositivos como comentaremos a seguir.

Destacaremos que durante os últimos anos, os QR-codes têm sido comuns em exposições de grande renome, tais como a $3 I^{\text {a }}$ Bienal de São Paulo, em 20I4, ou várias mostras do Instituto Tomie Ohtake (SP) que ofereceram uma audioguia mediante QR-codes como recurso para oferecer os conteúdos das obras que fizeram parte da exibição.

Mas essas experiências com os QR-Codes também estão presentes em instituições locais, similares aos espaços de atuação profissional na região da Grande Vitória, no Espírito Santo, apesar de estarem fora do grande eixo hegemônico do sistema da arte no Brasil e que centrará o nosso estudo. Nestas instituições o uso desta ferramenta tecnológica também está tendo um papel importante na difusão de conteúdos. Isto parece ser devido, em parte, ao fato de ser um recurso educacional bastante barato em comparação com a escolha de outras tecnologias cuja utilização é inviável dentro de orçamentos mais modestos.

Buscando analisar este fenômeno em outros locais análogos ao espaço cultural capixaba, citaremos alguns exemplos como o Museu do Mar e da Capitania (Ilhéus, Bahia), que desde 20I4, utiliza os QR-Codes para obter mais informações sobre algumas das peças expostas. Além disso, também se encontram em cinco idiomas diferentes que promovem a acessibilidade dos visitantes3.

Em outro caso, o Museu Paraense Emílio Goeldi, em Belém (PA), durante a Semana Nacional de Ciência e Tecnologia 2013 (SNCT), projetou um passeio pelo Parque Zoobotânico no qual os QR-Codes forneciam informações sobre algumas das espécies locais e suas propriedades e benefícios para a saúde4.

\footnotetext{
${ }^{3}<$ http://jornalsportnews.blogspot.com.br/20 /4//0/maramata-inicia-implantacao-de-qr-code.html>. Acesso em: $07 /$ setembro/2016.

${ }^{4}$ <http://www.brasil.gov.br/ciencia-e-tecnologia/2013/I0/museu-paraense-realiza-trilha-ecologi-
} 
Em suma, a usabilidade desses códigos, que podem ser contextualizados em qualquer ambiente expositivo, os torna como referência no acesso ao objeto e conteúdos culturais, como mostram os exemplos citados ou também alguns estudos acadêmicos no Brasil sobre o assunto (Lopes et al., 2012; Delinski et al., 20l2). No entanto, como mencionado anteriormente falando sobre as escassas pesquisas destinadas à relação entre os visitantes e os conteúdos digitais, estes são estudos que não fornecem resultados sobre o público e a eficácia deste recurso tecnológico em espaços expositivos reais, algo que foi objetivo principal deste estudo.

\section{Experiências avaliativas com QR-codes em espaços expositivos: dois casos de estudo}

Buscando estratégias de avaliar a eficácia e amplitude dessa ferramenta em espaços expositivos, foram realizadas duas experiências baseadas no uso de QR-codes em colaboração com duas exposições de arte na cidade de Vitória (ES). A primeira teve lugar no Palácio Anchieta, com motivo da exposição "O encantado" desenhos, pinturas e objetos de Attilio Colnago (20l4). Foi projetada uma aplicação com QR-codes similar aos exemplos em espaços expositivos mencionados anteriormente, na qual foram selecionadas seis das obras da exposição para colocar um código que levasse a um site com informações sobre a obra em questão. Nessa proposta se pretendeu fornecer uma visão mais ampla do processo criativo do artista para compreender a gênese e os procedimentos da obra apresentada em seu estado final ${ }^{5}$.

\section{MADONA COM FLORES}
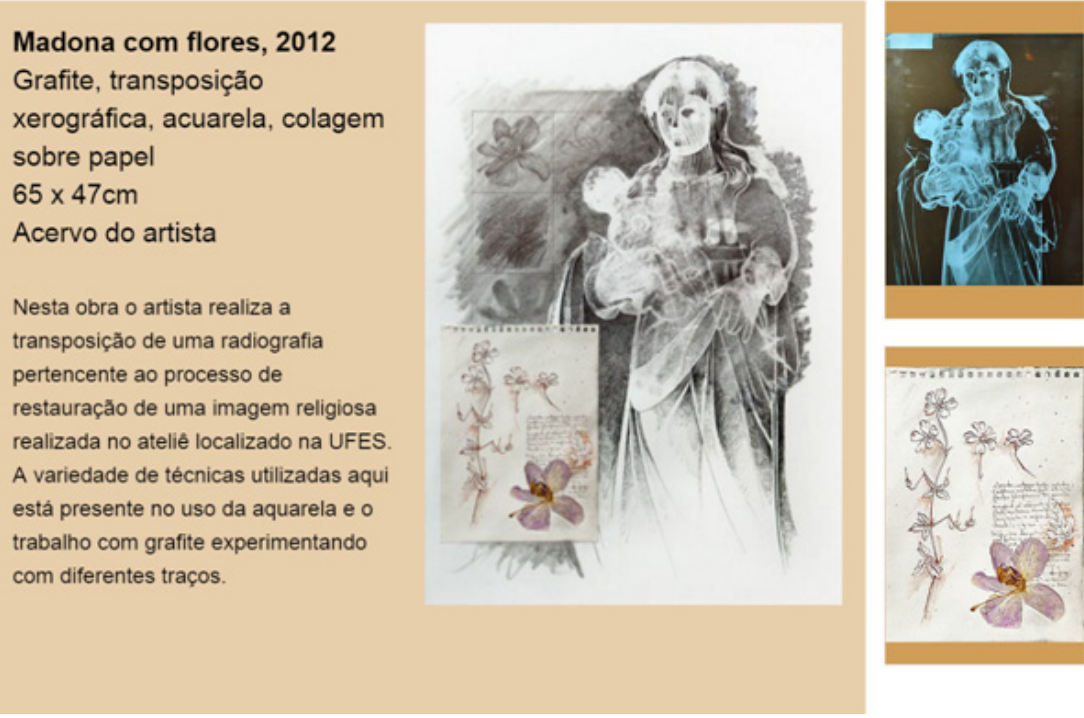

Nossa Sen...

Ler Mais 》>

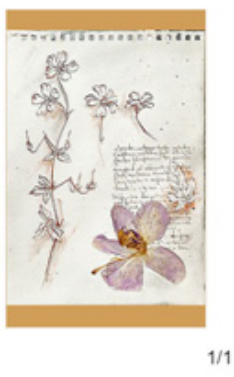

Figura I. Conteúdos digitais do QR code. Captura do autor.

ca-multimidia $>$. Acesso em: 08/setembro/2016.

${ }^{5}$ Site com os conteúdos digitais dos QR-codes: <http://attiliocolnago.wixsite.com/oencantado/saibamais>. 
EL VACÍO QUE DEJAS EN MÍ

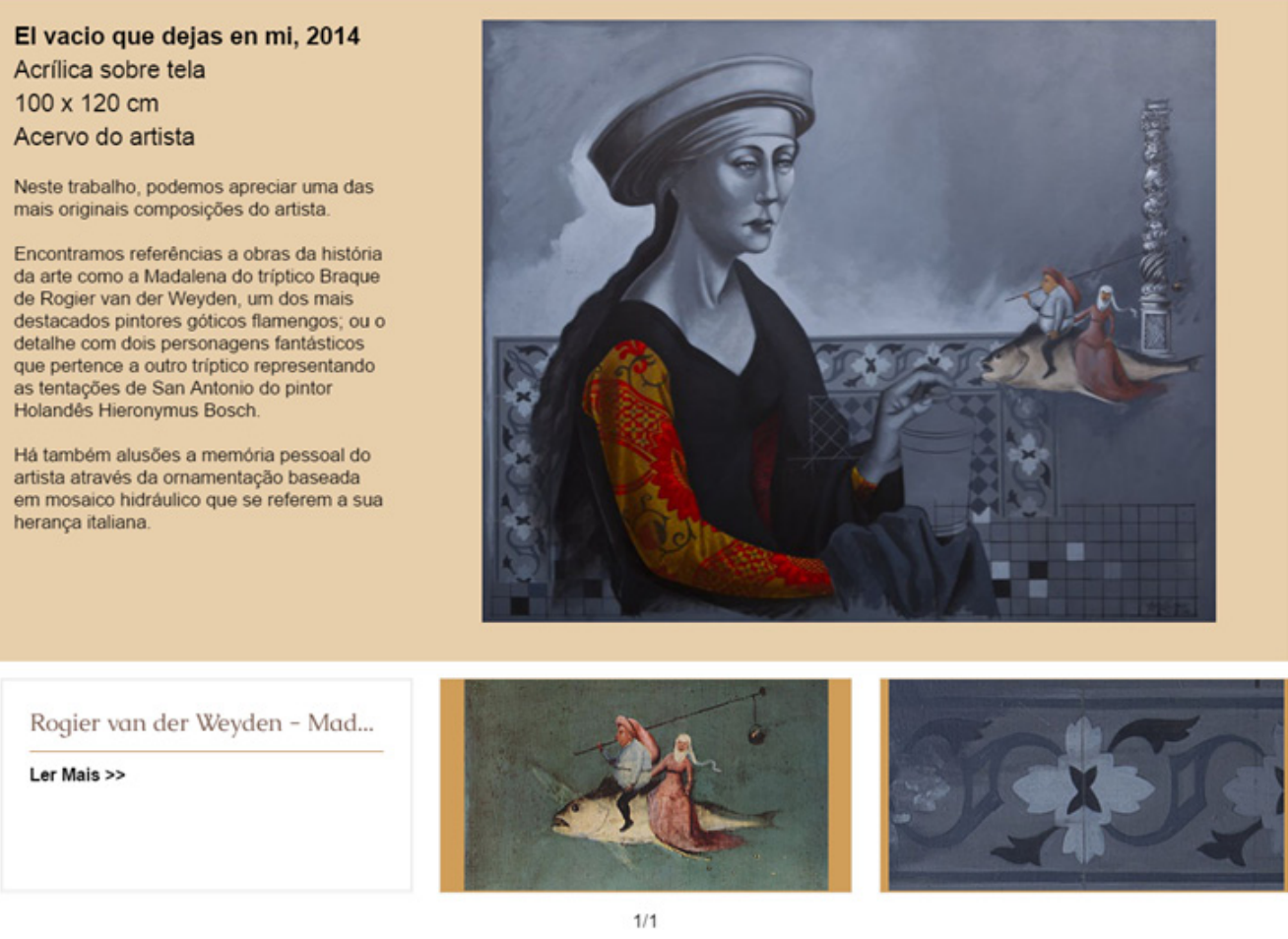

Figura 2. Conteúdos digitais do QR code. Captura do autor.

Neste caso, foram utilizados diferentes materiais que tinham sido fundamentais na gênese das obras e faziam parte do processo criativo do artista como estudos de composição, esboços preliminares, referências iconográficas ou documentos relativos à memória pessoal do artista. Desta maneira, cada QR-code dava acesso a um link que levava ao site onde estavam hospedados os conteúdos relacionados e que mostravam tanto as informações textuais como as imagens, permitindo interatuar e navegar mediante diversos links para encontrar mais detalhes e informações.

Finalmente, como parte deste estudo, se tentou determinar os resultados em pequena escala, utilizando uma ferramenta como Google Analytics, que é responsável por fornecer os dados de acesso a um determinado site. Assim, permitia monitorar a leitura dos QR-Codes usando um dos itens de Analytics que identifica o acesso à web desde dispositivos móveis, incluindo ambos os smartphones e tablets.

Partindo de resultados iniciais durante a primeira exposição, vários recursos alternativos foram usados durante uma segunda experiência em outra mostra que procurou promover uma relação mais estreita entre os visitantes e os conteúdos digitais oferecidos pela aplicação de QR-codes. Esse segundo cenário de validação foi no Centro Cultural Sesc "Glória", por ocasião da II edição da exposição Vitória em Arte (20I5). Aqui se reuniram varias obras de artistas locais e, especialmente, foram homenageados dois artistas com uma carreira importante no Estado. Os artistas Rosana Paste e Antonio Rosa tiveram um lugar de destaque no espaço de exposição sendo objeto, por tanto, da experiência com QR-codes6.

${ }^{6}$ Em relação à museografia, e como uma proposta de captação de público, foram elaborados alguns painéis 
Como no caso anterior no Palácio Anchieta, foram escolhidos seis trabaIhos que por sua especial relevância ou maior conteúdo eram ideais para expandir as informações mediante o uso dos códigos7. Mas, desata vez, as etiquetas de QR-codes foram acompanhadas com fragmentos de texto que avançavam os conteúdos digitais como uma forma de sugestionar ao visitante para ler o código com o seu celular. As figuras 2 e 3 apresentam algumas destas etiquetas com as respectivas obras.

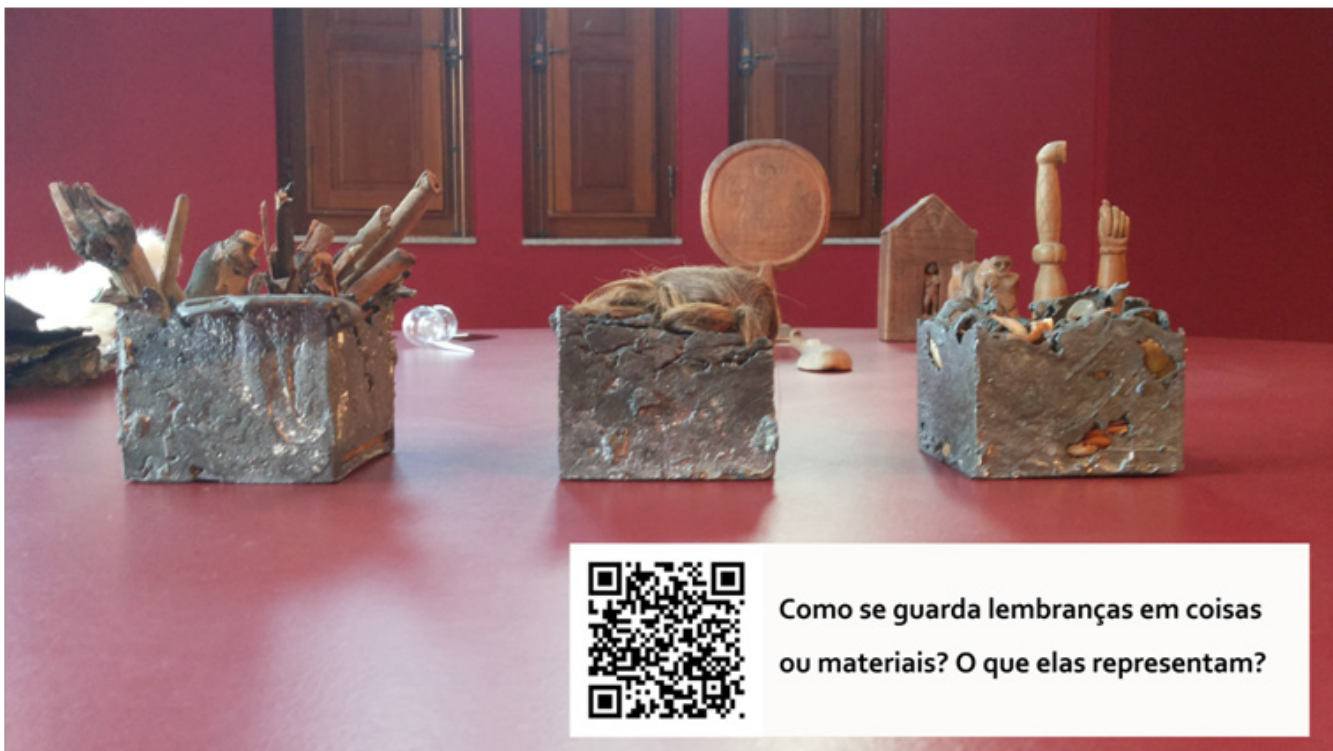

Figura 3. Imagem da obra A ilha de Rosana Paste e etiqueta QR-code. Foto do autor, 2015.

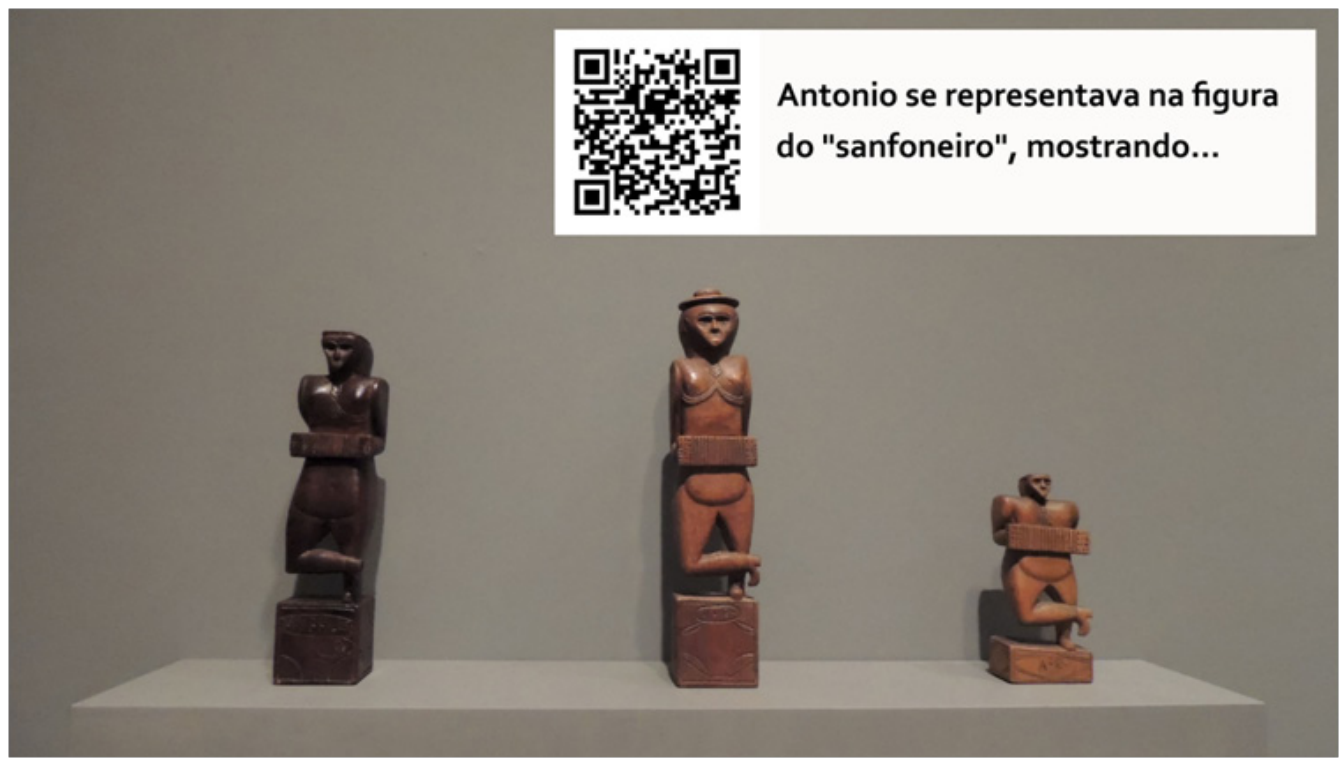

Figura 4. Imagem da obra O sanfoneiro de Antonio Rosa e etiqueta QR-code. Foto do autor, 2015.

explicativos sobre como usar os QR-Codes, indicando alguns leitores gratuitos e eficientes que podem ser descarregados das plataformas digitais como Beetag Reader.

${ }^{7}$ Site com os conteúdos digitais dos QR-codes: <http://vitoriaemartel I.wixsite.com/expo/saiba-mais---> 
Novamente, nesta segunda experiência se utilizou a ferramenta como Google Analytics, que permitiu monitorar a leitura dos QR-codes identificando o acesso à web desde dispositivos móveis e que permitiriam comparar os resultados com a experiência anterior.

\section{Resultados e interpretação de dados: uso de QR-code e público em espaços expositivos}

Em relação aos resultados de público obtidos com Google Analytics, um dos primeiros dados que nos dá essa ferramenta é o número de visitantes que acessaram as informações contidas nos QR-codes. Assim, enquanto que na exposição realizada em 2014 o número atingiu apenas 28 pessoas, durante a segunda experiência em 2015, houve um relativo maior interesse, dado que foram 45 os visitantes que escanearam os códigos.

Outro dos dados obtidos através do monitoramento com a ferramenta Google Analytics se refere ao comportamento dos visitantes e, mais especificamente, ao tempo dedicado na leitura das informações digitais de cada uma das obras. O tempo médio para cada um dos códigos durante a mostra de 2014 foi de 3:25 minutos, enquanto que, por seu lado, o tempo dedicado na exposição de 2015 foi de 2:25 minutos. Ambos dados, em resposta ao comprimento curto de textos e de informações visuais básicas, evidenciam um tempo suficiente para se concentrar nos conteúdos.

Um fato notável é que o tempo dedicado à visualização dos conteúdos foi menor na segunda experiência. Isto parece se dever a que neste último caso não se ofereciam os conteúdos mediante vários links que existiam na web da exposição de 2014, os quais permitiram uma maior interatividade do usuário e, portanto, um tempo mais prolongado na visitação.

\section{Conclusões}

Na sequência dos resultados podemos confirmar a ideia de que são precisos estudos de publico que nos falem sobre a adequação de uma determinada tecnologia como mediação nos espaços de exposição. No caso dos QR-codes se demonstrou que esta tecnologia ainda aparece como algo alheio ao discurso expositivo e que como um recurso de mediação não encontra uma aplicação satisfatória.

Embora até certo ponto se alcançassem os objetivos na segunda experiência, aumentando o número de visitantes que usaram os $Q R$-codes, o fato é que o aumento na cifra de visitantes não é realmente significativo se falamos de exposições pelas quais passaram centenas de pessoas.

Apesar desses resultados, se evidenciou a idoneidade de uma preparação prévia e um trabalho elaborado na edição de conteúdos digitais de forma qualitativa, da mesma forma que nas visitas monitoradas se oferecem diferentes níveis de mediação em função do grupo de visitantes.

Também se evidenciou que o interesse dos visitantes era importante, e que mediante a presença de informações, através do espaço digital, torna-se possível expandir exponencialmente a comunicação e difusão da obra artística desde o espaço expositivo, que é desdobrado no mundo digital e integrado como parte do discurso museográfico.

Cabe aqui refletir que a falta de uma curadoria tecnológica adequada parece provocar que a mediação das novas tecnologias na aprendizagem não-formal dos espaços expositivos seja um elemento que, dentro do conjunto da exposi- 
ção, para o público, pareça não acrescentar à obra ou à sua recepção ampliando a experiência estética em curso. Isto nos leva a perceber certo desinteresse no uso dessas tecnologias por parte do visitante nesses espaços fora dos grandes centros culturais do Brasil.

Acreditamos que os educadores tem um papel decisivo nisto, em especial os arte-educadores, os quais deveriam assumir o papel de mediadores entre os visitantes e essas novas ferramentas tecnológicas para que esta relação sensível da experiência estética seja acrescentada e consiga ser eficaz dentro dos espaços expositivos na atualidade.

\section{Referências}

ALEXANDER, Edward P. Museums in Motion. Nashville:American Association for State and Local History, 1979.

ASCOTT, Roy. The Museum of the Third Kind. InterCommunication, $\mathrm{n}^{\circ} \mathrm{I5}$, Nov., 1996. Disponível em: <http://www.ntticc.or.jp/pub/ic_mag/ic0I5/ascott/ ascott_e.html> Acesso em: 04/setembro/20l6.

BARBOSA, Ana Mae. Dilemas da Arte/Educação como mediação cultural em namoro com as tecnologias contemporâneas. In: (Org). Arte/Educação contemporânea: consonâncias internacionais. São Paulo: Cortez, 2005. p. 98- I I 2.

BEIGUELMAN, Giselle. Arte pós-virtual: Criação e agenciamento no tempo da Internet das Coisas e da próxima natureza. In: PESSOA, F (org.). Cyber-arte-cultura - A trama das redes. Seminários Internacionais Museu Vale 201 3. Vila Velha: Museu Vale, 20I3, pp. I 47 - I7I.

DELINSKI, V.; CANDIDO, F.; CERUTTI, D.; CELINSKI, T.; PACHECO, M. O uso de QR-code em material didático para o museu virtual da Universidade Estadual de Ponta Grossa. In: $10^{\circ}$ CONEX. Ponta Grossa. Anais do CONEX, 2012. Disponível em: <http://www.uepg.br/proex/anais/trabalhos/I72.pdf>. Acesso em: I0/ setembro/2016.

LOPES, U.; FERREIRA, R.; SCHERER, D. Uso de QR Code e Realidade Aumentada como suporte a visitação de museu. RENOTE - Revista Novas Tecnologias na Educação, v. I0, n. 2, dec., 2012. Disponível em: <http://seer.ufrgs.br/renote/ article/view/36|32>. Acesso em: 05/setembro/20l6.

SCHWEIBENZ,Werner.The "Virtual Museum": New Perspectives For Museums to Present Objects and Information Using the Internet as a Knowledge Base and Communication System. In: ZIMMERMANN, Harald H.; SCHRAMM, Volker (Org.): Knowledge Management und Kommunikations systeme, Workflow Management, Multimedia, Knowledge Transfer. Konstanz: UVK Verlagsgesellschaft $\mathrm{mbH}$, 1998. Pp. 185-200. Disponível em: <http://www.informationswissenschaft.org/ wp-content/uploads/isi/isi l998/l4_isi-98-dv-schweibenz-saarbruecken.pdf>. Acesso em: 24/setembro/20I6.

WHITCHURCH, M. J. A Quick Response: QR Code Use at the Harold B. Lee Library. The Reference Librarian, vol. 53, n. 4, pp. 392 - 402, out., 2012.

Artigo recebido em novembro de 2016.Aprovado em junho 2017. 